\title{
Lipofundin-Induced Hyperlipidemia Promotes Oxidative Stress and Atherosclerotic Lesions in New Zealand White Rabbits
}

\author{
Livan Delgado Roche, ${ }^{1}$ Emilio Acosta Medina, ${ }^{1}$ Ángela Fraga Pérez, ${ }^{1}$ \\ María A. Bécquer Viart, ${ }^{1}$ Yosdel Soto López, ${ }^{2}$ Viviana Falcón Cama, ${ }^{3}$ Ana M. Vázquez López, ${ }^{2}$ \\ Gregorio Martínez-Sánchez, ${ }^{4}$ and Eduardo Fernández-Sánchez ${ }^{1}$ \\ ${ }^{1}$ Center of Studies for Research and Biological Evaluations, Pharmacy and Food Science College, University of Havana, \\ PO. Box 13 600, La Coronela, La Lisa, Havana 13600, Cuba \\ ${ }^{2}$ Department of Antibody Engineering, Center of Molecular Immunology, Havana 11600, Cuba \\ ${ }^{3}$ Department of Electron Microscopy, Center for Genetic Engineering and Biotechnology, Havana 10600, Cuba \\ ${ }^{4}$ MediNat, 60021 Ancona, Italy \\ Correspondence should be addressed to Livan Delgado Roche, ldelgadoroche@gmail.com
}

Received 1 April 2011; Revised 21 June 2011; Accepted 23 July 2011

Academic Editor: Spencer D. Proctor

Copyright ( $) 2012$ Livan Delgado Roche et al. This is an open access article distributed under the Creative Commons Attribution License, which permits unrestricted use, distribution, and reproduction in any medium, provided the original work is properly cited.

\begin{abstract}
Atherosclerosis represents a major cause of death in the world. It is known that Lipofundin 20\% induces atherosclerotic lesions in rabbits, but its effects on serum lipids behaviour and redox environment have not been addressed. In this study, New Zealand rabbits were treated with $2 \mathrm{~mL} / \mathrm{kg}$ of Lipofundin for 8 days. Then, redox biomarkers and serum lipids were determined spectrophotometrically. On the other hand, the development of atherosclerotic lesions was confirmed by eosin/hematoxylin staining and electron microscopy. At the end of the experiment, total cholesterol, triglycerides, cholesterol-LDL, and cholesterolHDL levels were significantly increased. Also, a high index of biomolecules damage, a disruption of both enzymatic and nonenzymatic defenses, and a reduction of nitric oxide were observed. Our data demonstrated that Lipofundin 20\% induces hyperlipidemia, which promotes an oxidative stress state. Due to the importance of these phenomena as risk factors for atherogenesis, we suggest that Lipofundin induces atherosclerosis mainly through these mechanisms.
\end{abstract}

\section{Introduction}

Atherosclerosis is a chronic vascular disease and a leading cause of death in the western world. It is well established that hyperlipidemia and oxidative stress (OS) are major contributors to atherogenic development [1]. The retention of low-density lipoproteins (LDL) in the arterial wall [2] and their oxidation by reactive oxygen species (ROS) initiates a complex series of biochemical and inflammatory reactions $[3,4]$. Oxidized LDL (ox-LDL) are internalized by macrophages through the scavenger receptors, leading to foam cell formation [5]. Furthermore, oxidized cholesterol products present in blood and in arterial plaques increase cholesterol biosynthesis, affect plasma membrane structure, cell proliferation, and cell death, and promotes atherosclerosis development [6].

The rabbit is one of the most widely used animal models in atherosclerosis research. One strategy to induce atherosclerotic lesions in these animals is through an intravenous administration of Lipofundin 20\%, a lipid-rich emulsion used in parenteral nutrition, which produces aortic lesions, characterized by subendothelial lipid accumulation, intimal thickening, and a distortion of vascular tissue architecture $[7,8]$. The impact of Lipofundin $20 \%$ administration on lipid levels and redox environment in New Zealand white (NZW) rabbits had not been studied. In the present work, we demonstrated that Lipofundin 20\% induces a hyperlipemic 
state and a systemic/aortic oxidative stress, which can lead to atherosclerotic lesions development.

\section{Materials and Methods}

2.1. Animals. Standard NZW male rabbits, weighing 2.0$2.5 \mathrm{~kg}$ and 12 weeks old, were obtained from CENPALAB (Bejucal, Havana, Cuba). Rabbits were housed under conventional conditions exposed to light-dark cycle of $12 \mathrm{~h}$ with free access to water and food. Animal studies were performed with the approval of Pharmacy and Food Sciences College Institutional Animal Ethical Committee. All procedures were performed in accordance with the guidelines stipulated by the Institutional Animal Care Committee and the European Union Guidelines for animal experimentation.

2.2. Lipofundin Composition. Lipofundin MCT/LCT $20 \%$ (Braun Melsungen AG, Melsungen, Germany) is a lipid emulsion containing soya oil $100 \mathrm{~g}$, medium-chain triglycerides $100 \mathrm{~g}$, glycerol $25 \mathrm{~g}$, egg lecithin $12 \mathrm{~g}, \alpha$-tocopherol $170 \pm 40 \mathrm{mg}$, and sodium oleate/water for injection in sufficient quantity to $1000 \mathrm{~mL}$.

2.3. Experimental Design. Two groups of 10 rabbits were used in the study. The first group received an intravenous injection of phosphate-buffered saline (PBS), pH 7,4 (control group), and the second one received a slow intravenous injection of $2 \mathrm{~mL} / \mathrm{kg}$ of Lipofundin MCT/LCT 20\%, as an infusion during 1-2 $\min [7,8]$. This procedure was repeated daily during a period of 8 days. On day 9 , the animals were anesthetized with ketamine hydrochloride ( $5 \mathrm{mg} / \mathrm{kg}$ i.m.) and euthanized with an overdose of sodium pentobarbital (90 mg/kg, i.v.). (Abbott Laboratories, Mexico SA de CV, Mexico), and the vascular system was perfused with $\mathrm{NaCl}$ $0.9 \%$ solution at $4^{\circ} \mathrm{C}$. Then, aortas were excised from the aortic arch to abdominal segment, and adventitial fat was removed. Aortic arches were used for histopathology and redox evaluations due to the preferential development of Lipofundin 20\%-induced atherosclerotic lesions in this segment [8]. For each evaluation, the samples of five animals per group were used.

2.4. Serum Sample Collection. Blood samples $(3 \mathrm{~mL})$ were obtained on day 0 (before Lipofundin administration) and on day 9 (at the end of the study), for biochemical analyses. Blood was withdrawn from the rabbit's marginal ear vein. These samples were immediately centrifuged at $2500 \mathrm{~g}$, at $4^{\circ} \mathrm{C}$ for $10 \mathrm{~min}$. The serum was collected and aliquots were stored at $-80^{\circ} \mathrm{C}$ until analysis.

2.5. Aortic Homogenate Preparation. Aortic arches were placed in ice-cold $0.1 \mathrm{~mol} / \mathrm{L}$ Tris- $\mathrm{HCl}$ buffer, $\mathrm{pH}$ 7,6 containing $1.0 \mathrm{mmol} / \mathrm{L}$ EDTA and $0.2 \mathrm{mmol} / \mathrm{L}$ butylated hydroxytoluene (buffer A) and macerated before homogenization in a tissue homogenizer (Edmund Bühler LBMA, Germany). Homogenized tissue was then centrifuged at $4500 \mathrm{~g}$ for $20 \mathrm{~min}$ at $4^{\circ} \mathrm{C}$, and the supernatants were collected and stored at $-80^{\circ} \mathrm{C}$ until redox biomarkers determinations.

\subsection{Histopathology}

2.6.1. Eosin-Hematoxylin Staining. Aortic arches were rinsed in PBS, pH 7,4, transversally cut, and fixed in $10 \%$ formaldehyde solution. Samples were then embedded in paraffin. Five-micrometer tissue sections were cut, air-dried on glass slides, deparaffinized, and rehydrated. Finally, tissue sections were stained with eosin and hematoxylin (HE) under standard procedures. The sections were analyzed in an optic microscope Olympus BX51.

\subsection{Ultrastructural Analysis}

2.7.1. Electron Transmission Microscopy. For transmission electron microscopy (TEM), samples from rabbit aortic arch were fixed for $1 \mathrm{~h}$ at $4^{\circ} \mathrm{C}$ in $3.2 \%$ glutaraldehyde (Agar Scientific, UK), 0.1 M phosphate buffer ( $\mathrm{pH} 7,4$ ) and postfixed in $1 \% \mathrm{OsO}_{4}$ for $1 \mathrm{~h}$. After graded ethanol dehydration, samples were embedded in Spurr low-viscosity epoxy resin for $24 \mathrm{~h}$ at $37^{\circ} \mathrm{C}$. Ultrathin sections were cut into 400-500 $\AA$ thick slice with an ultramicrotome (NOVA, LKB), counterstained with uranyl acetate and lead citrate, and analyzed in a TEM (JEOL JEEM-2000EX, JEOL, Japan).

2.7.2. Serum Lipid Assay. Serum total cholesterol, triglycerides, LDLc, and HDLc were determined using commercial enzymatic kits (Randox, Crumlin, UK).

2.7.3. Redox Biomarkers Determinations. All biochemical parameters were determined by spectrophotometric methods using a Pharmacia 1000 Spectrophotometer (Pharmacia LKB, Uppsala, Sweden). Total proteins levels were determined using the method described by Bradford [9] with bovine serum albumin as standard. SOD activity was determined by using RANSOD kit (catalogue no. SD 125, Randox Labs, Crumlin, UK), where xanthine and xanthine oxidase were used to generate superoxide anion radicals $\left(\mathrm{O}_{2}^{\bullet-}\right)$, which react with 2-(4-iodophenyl)-3-(4nitrophenol)-5-phenyltetrazolium chloride (INT) to form a red formazan dye. SOD activity was measured by the inhibition degree of this reaction. Catalase (CAT) activity was determined by following the decomposition of hydrogen peroxide $\left(\mathrm{H}_{2} \mathrm{O}_{2}\right)$ at $240 \mathrm{~nm}$ at $10 \mathrm{~s}$ intervals during $1 \mathrm{~min}$ [10].

After precipitation of thiol proteins, the reduced glutathione (GSH) levels were measured according to the method of Sedlak and Lindsay [11] with Ellman's reagent (5,5' dithiobis-2-nitrobenzoic acid) (Sigma St. Louis, MO, USA), and the absorbance was measured at $412 \mathrm{~nm}$. Purified GSH (Sigma St. Louis, MO, USA) was used to generate standard curves.

The advanced oxidation protein products (AOPPs) were measured as described previously [12]. Briefly, samples in PBS $(1 \mathrm{~mL})$ were treated with $50 \mu \mathrm{L}$ of potassium iodide $1.16 \mathrm{M}$ followed by the addition of $100 \mu \mathrm{L}$ of acetic acid. The absorbance was immediately read at $340 \mathrm{~nm}$. AOPP concentration was expressed as $\mu \mathrm{M}$ of chloramines- $\mathrm{T}$.

Concentration of malondialdehyde (MDA) was determined using the LPO-586 kit obtained from Calbiochem (La Jolla, CA, USA). In the assay, the production of a stable 


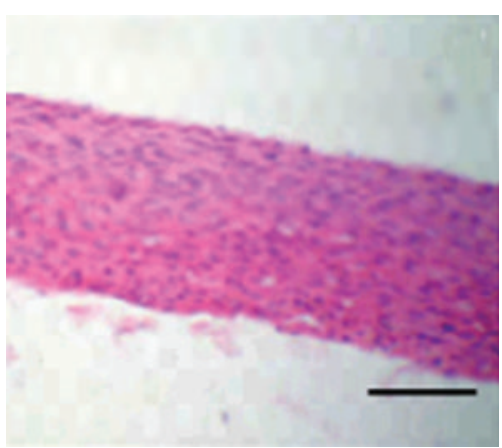

(a)

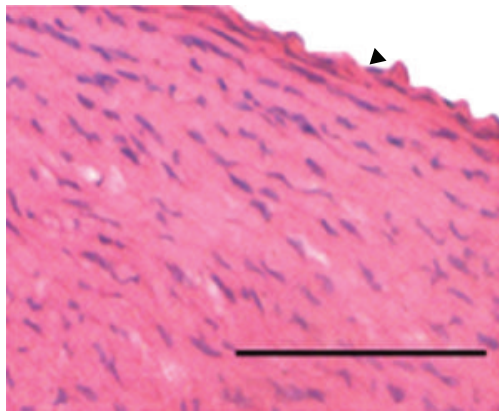

(c)

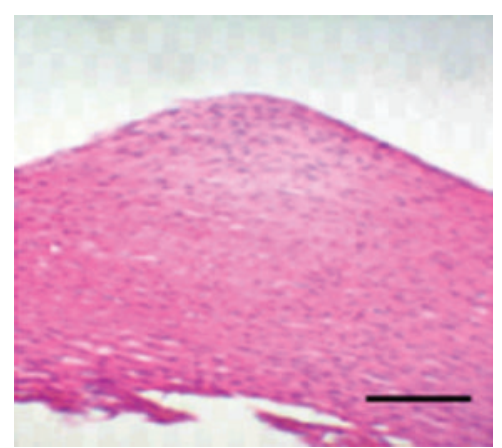

(b)

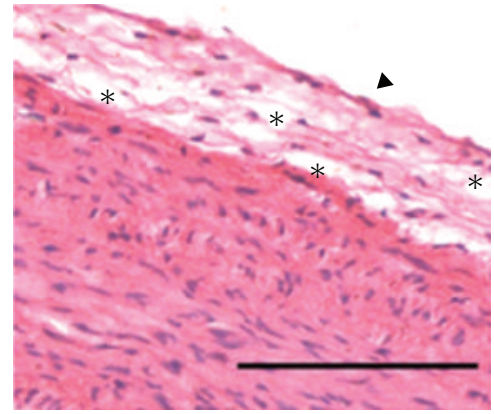

(d)

FIGURE 1: Histopathological analysis of rabbit's aortic tree. Eosin/hematoxylin staining reveals a normal morphology of aortas in control animals (a) and (c), while aortas of Lipofundin group show an intimal thickening, characterized by a vascular tissue architecture distortion and large extracellular spaces, probably filled with lipids (asterisks) (b) and (d). Arrow head: endothelial cells. Magnification 10× (a) and (b) and $40 \times(\mathrm{c})$ and (d). Scale bar, $20 \mu \mathrm{m}$.

chromophore after 40 min of incubation at $45^{\circ} \mathrm{C}$ was measured at $586 \mathrm{~nm}$. For standards, freshly prepared solutions of malondialdehyde bis (dimethyl acetal) (Sigma St. Louis, MO, USA) were employed and assayed under identical conditions $[13,14]$.

In order to determine susceptibility to lipid peroxidation and total reactive antioxidant power (TRAP), the samples were incubated with a solution of copper sulphate (final concentration $2 \mathrm{mM}$ ) at $37^{\circ} \mathrm{C}$ for $24 \mathrm{~h}$. The peroxidation potential (PP) was calculated by subtracting the MDA levels before the induction of lipid peroxidation from the one obtained at $24 \mathrm{~h} \mathrm{[15].}$

Nitrites $\left(\mathrm{NO}_{2}^{-}\right)$level, as a surrogate marker of nitric oxide $\left(\mathrm{NO}^{\bullet}\right)$, were determined converting nitrates to nitrites using nitrate reductase (Boehringer Mannheim Italy SpA, Milan, Italy). Then, Griess reagent ( $1 \%$ sulphanilamide, $0.1 \% \mathrm{~N}$-(1-Naphthyl)-ethylenediamine dihydrochloride in $0.25 \%$ phosphoric acid) was added [16]. Samples were incubated at room temperature for $10 \mathrm{~min}$, and absorbance was measured at $540 \mathrm{~nm}$.

2.8. Statistical Analysis. Statistical analysis was performed using the SPSS program for Windows (version 11.5, SPSS Inc). Bartlett's Box-test was used to test the homogeneity of variance. Differences between groups were determined by student's $t$-test (two-tailed). Data were expressed as the mean \pm standard deviation $(\mathrm{SD})$. A $P$ value of $<0.05$ was considered statistically significant.

\section{Results}

3.1. Histopathology. The HE staining of aortic arch sections from control rabbits showed neither intimal thickening nor distortion in the vascular tissue architecture (Figures 1(a) and $1(\mathrm{c}))$. In contrast, aortic sections from those animals who received intravenously $2 \mathrm{~mL} / \mathrm{kg}$ of Lipofundin $20 \%$ during 8 days showed a thickening of the intima with apparent lipid accumulation and distortion of tissue architecture (Figures 1(b) and 1(d)).

Nonrelevant disease or abnormalities in other organs were detected by macroscopic and microscopic examination.

3.2. Ultrastructural Analysis. On the other hand, the ultrastructural analysis confirmed the results observed by light microscopy. In the animals treated with Lipofundin was observed an endothelial damage characterized by a loss of endothelium integrity and the presence of abundant foam cells and myofibroblasts in the intima and media layers. Also, we observed a high extracellular lipid accumulation and collagen fibers deposition (Figures 2(c), 2(d), 2(e), 2(f)). No alterations in the aortic artery wall of control rabbits were observed (Figures 2(a) and 2(b)).

3.3. Serum Lipids. Serum total cholesterol, triglycerides, LDLc, and HDLc levels showed a significant increase $(P<$ 0.05 ) in those animals who were treated during 8 days with the lipid-rich emulsion Lipofundin, while no significant 


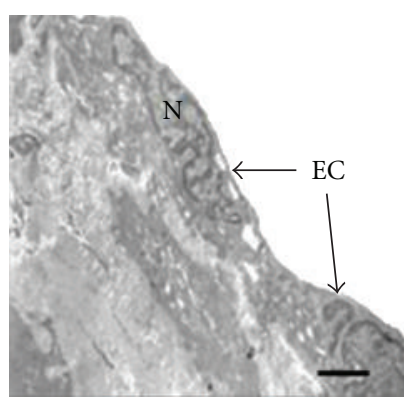

(a)

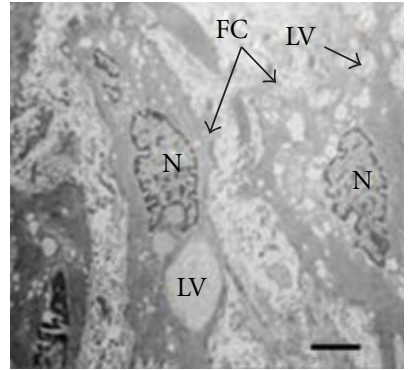

(c)

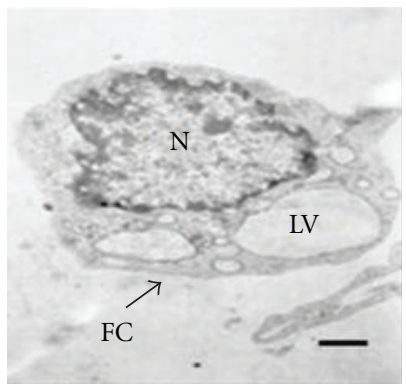

(e)

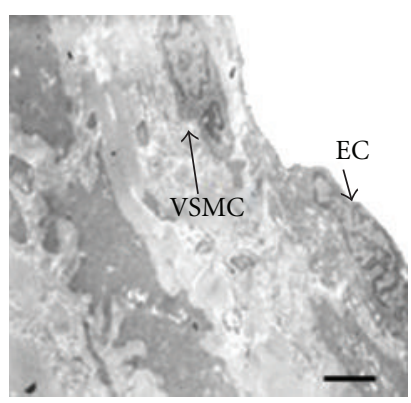

(b)

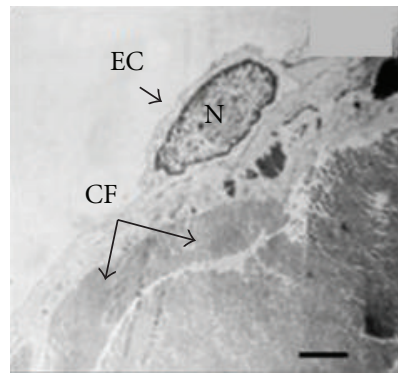

(d)

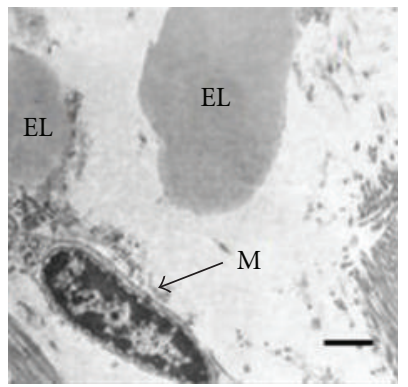

(f)

FIgURE 2: Ultrastructural analysis. Panels (a) and (b) correspond to animals of control group, while panels (b), (c), (d), and (e) show the effects of Lipofundin administration on atherosclerotic lesion formation. EC: endothelial cells, EL: extracellular lipids, VSMC: vascular smooth muscle cells, N: nucleus, FC: foam cells, LV: lipid vacuolization, CF: collagen fibers, M: myofibroblasts. Scale bar $1 \mu \mathrm{m}(\mathrm{a}, \mathrm{b}, \mathrm{c}, \mathrm{d})$, $500 \mathrm{~nm}(\mathrm{e}, \mathrm{f})$.

changes in serum lipids were observed in the control rabbits throughout the study (Table 1).

3.4. Redox Biomarkers. Table 2 shows the behavior of serum and aortic redox parameters in both groups. The biomolecules damages markers were significantly $(P<0.05)$ modified after 8 days of Lipofundin administration compared to nontreated group. At the end of the experimental period, the MDA levels, one of the end-products of lipid peroxidation, were higher in Lipofundin-treated animals compared with controls. Besides, Lipofundin treatment also caused a rise of AOPP levels in comparison with control group. The activity of both antioxidant enzymes SOD and CAT were significantly higher $(P<0.05)$ in Lipofundin group at the end of the experiment compared to control rabbits. The $\mathrm{NO}_{2}^{-}$levels and GSH concentration decreased significantly after 8 days of Lipofundin treatment in comparison to those of untreated animals $(P<0.05)$. Finally, the susceptibility to lipid peroxidation was higher in
TABLE 1: Effects of Lipofundin on serum lipid profile. Values represent the mean \pm standard deviation. Asterisks represent statistical differences $(P<0.05)$.

\begin{tabular}{lcc}
\hline & Control & Lipofundin \\
\hline TC, mmol/L & $1.78 \pm 0.06$ & $3.10 \pm 0.13^{*}$ \\
TG, mmol/L & $1.51 \pm 0.03$ & $2.73 \pm 0.07^{*}$ \\
HDLc, $\mathrm{mmol} / \mathrm{L}$ & $0.76 \pm 0.04$ & $1.20 \pm 0.04^{*}$ \\
LDLc, $\mathrm{mmol} / \mathrm{L}$ & $0.18 \pm 0.01$ & $0.83 \pm 0.03^{*}$ \\
\hline
\end{tabular}

those animals who received Lipofundin. After 8 days, in these animals was observed a significant increase of $\mathrm{PP}(P<0.05)$, compared to the one calculated in controls.

\section{Discussion}

The histopathological analyses of the aortic sections from rabbits treated with Lipofundin 20\% demonstrated the 
TABLE 2: Effects of Lipofundin on redox biomarkers. Values represent the mean \pm standard deviation. Asterisks represent statistical differences $(P<0.05)$. The concentration of aortic parameters is expressed per milligrams of total proteins $(\mathrm{Pr})$.

\begin{tabular}{|c|c|c|}
\hline & Control & Lipofundin \\
\hline \multicolumn{3}{|c|}{ Systemic redox biomarkers } \\
\hline $\mathrm{MDA}, \mu \mathrm{M}$ & $2.69 \pm 0.07$ & $6.24 \pm 0.28^{*}$ \\
\hline AOPP, $\mu \mathrm{M}$ of chloramines & $11.50 \pm 0.73$ & $16.22 \pm 0.47^{*}$ \\
\hline $\mathrm{PP}, \mu \mathrm{M}$ of MDA & $4.63 \pm 0.18$ & $9.13 \pm 0.34^{*}$ \\
\hline CAT, U/L/min & $351.13 \pm 19.03$ & $477.50 \pm 30.46^{*}$ \\
\hline $\mathrm{SOD}, \mathrm{U} / \mathrm{mL} / \mathrm{min}$ & $22.03 \pm 26.44$ & $32.00 \pm 1.60^{*}$ \\
\hline $\mathrm{NO}_{2}, \mu \mathrm{M}$ & $179.18 \pm 11.44$ & $134.33 \pm 5.09^{*}$ \\
\hline $\mathrm{GSH}, \mu \mathrm{M}$ & $309.03 \pm 26.44$ & $191.21 \pm 8.26^{*}$ \\
\hline \multicolumn{3}{|c|}{ Aortic redox biomarkers } \\
\hline $\mathrm{MDA}, \mu \mathrm{M} / \mathrm{mgPr}$ & $18.49 \pm 2.04$ & $27.42 \pm 2.55^{*}$ \\
\hline $\begin{array}{l}\text { AOPP, } \mu \mathrm{M} \text { of } \\
\text { chloramines } / \mathrm{mgPr}\end{array}$ & $12.45 \pm 1.21$ & $24.25 \pm 1.86^{*}$ \\
\hline $\mathrm{PP}, \mu \mathrm{M}$ of $\mathrm{MDA} / \mathrm{mgPr}$ & $13.81 \pm 1.83$ & $25.26 \pm 2.29^{*}$ \\
\hline $\mathrm{CAT}, \mathrm{U} / \mathrm{L} / \mathrm{min} / \mathrm{mgPr}$ & $1023.60 \pm 26.89$ & $1609.68 \pm 84.37^{*}$ \\
\hline $\mathrm{SOD}, \mathrm{U} / \mathrm{mL} / \mathrm{min} / \mathrm{mgPr}$ & $62.37 \pm 3.93$ & $105.39 \pm 9.82^{*}$ \\
\hline $\mathrm{NO}_{2}, \mu \mathrm{M} / \mathrm{mgPr}$ & $95.29 \pm 2.54$ & $43.96 \pm 6.03^{*}$ \\
\hline $\mathrm{GSH}, \mu \mathrm{M} / \mathrm{mgPr}$ & $166.70 \pm 12.82$ & $71.59 \pm 10.89^{*}$ \\
\hline
\end{tabular}

capacity of Lipofundin to induce atherosclerotic lesions. As described above, an intimal thickening and a distortion of tissue architecture was observed by EH staining. Electron microscopy confirmed the presence of foam cells, extracellular lipid accumulation, collagen fibers deposition, vascular smooth muscle cells (VSMC) migration, the presence of myofibroblasts, and also the loss of endothelium integrity. These events, induced by Lipofundin $20 \%$, contribute with the development and progression of atherosclerosis.

At the end of the experiment, we observed high serum levels of triglycerides, total cholesterol, LDLc, and HDLc in the animals treated with Lipofundin $20 \%$ in comparison to control rabbits. Indeed, there is a causal relationship between the elevated plasma lipids and the development of atherosclerotic lesions [17-19].

Lipofundin 20\%-induced hyperlipidemia could be associated with the high content of triglycerides in this emulsion. High levels of exogenous triglycerides promote ApoB100 and cholesterol synthesis and eventually the assembly of very low-density lipoproteins (VLDL) [20]. In fact, Lipofundin $10 \%$ caused a $60 \%$ increase in total serum cholesterol after parenteral administration in a human study [21].

In addition, there is a mutual exchange of lipids and apolipoproteins between serum lipoproteins and the infused triglyceride/phospholipid particles [22]. The increase of HDLc may be determined by a physiological response against the elevated LDLc levels. It is known that HDL protect from atherosclerotic development. However, based on recent animal and epidemiological studies, it appears that in addition to quantity [23] other properties of HDL, such as antioxidant and anti-inflammatory power, are necessary for atheroprotection $[24,25]$.
In this study, we demonstrated that Lipofundin-induced hyperlipidemia was associated with a systemic and aortic OS. Strong evidences for the involvement of free radicals production in the onset of hyperlipidemia have been reported previously [26]. Chronic generation and sustained high toxic levels of ROS are associated with several pathological conditions including cardiovascular diseases such as atherosclerosis [27]. During atherosclerotic lesions development, cellular damages take place through mechanisms involving lipid peroxidation and oxidative modifications of proteins [28]. On the other hand, a disruption of antioxidant enzymes activity and a drastic reduction of nonenzymatic defenses are also observed during atherogenesis [29]. High levels of MDA in the sera and aortic tissue from rabbits bearing atherosclerotic lesions, compared with those from control group, suggest the role of LPO in the loss of redox cellular status in the former animals which were under atherogenic stimuli caused by Lipofundin treatment. MDA levels have been considered not only an indicator of OS, but also as a biochemical marker of atherogenesis [30, 31].

Oxidative modifications of proteins have been also implicated in atherosclerosis [32]. Through AOPP determination, we measured the chlorinated proteins levels, caused by myeloperoxidase-derived hypochlorous acid ( $\mathrm{HOCl})$. It has been shown that $\mathrm{HOCl}$-modified proteins are present in atherosclerotic lesions and predict the progression of the disease [5]. The high levels of AOPP in those animals that received the lipid emulsion suggest an active role of macrophages infiltration and inflammatory process in the development of atherosclerotic lesions in the present animal model.

Antioxidant defenses, as expression of the balance between generation and inactivation of oxidized metabolites, represent a useful tool to examine the redox status $[33,34]$. In our study, the higher activity of extracellular SOD, detected in the animals treated with Lipofundin, could be associated with an increase in $\mathrm{O}_{2}^{--}$generation, typically produced by foam cells and macrophages at atherosclerotic lesion sites [35]. Also, in atherogenic process, there is an increase in vascular NADPH oxidase activity, the main source of $\mathrm{O}_{2}^{--}$in the vasculature [36].

CAT is another antioxidant enzyme present in the vasculature, which plays an important role on redox environment maintenance [37]. In our study, we found a high activity of the enzyme in animals treated with Lipofundin. During the beginning and development of atherogenic lesions, the enzyme gene expression increases and in this way contributes to retard the disease progression $[38,39]$. Also, it has been shown that in early steps of atherogenesis CAT activity is incremented in response to oxidant stimulus mediated by oxLDL and ROS such as $\mathrm{H}_{2} \mathrm{O}_{2}$ and lipoperoxides [40].

During atherogenesis, the reactive molecules that are produced have the potential to deplete the surrounding cells of their GSH levels, affecting their antioxidant defenses and detoxification pathways [41]. Our results showed a significant depletion of serum and aortic GSH levels in the animals treated with the lipid emulsion compared to the control rabbits. This fact could be associated with the Lipofundin-mediated ROS generation and with the 
high concentration of biomolecules damages detected in Lipofundin-treated animals.

Finally, we evaluated the behaviour of $\mathrm{NO}_{2}^{-}$levels, as a marker of $\mathrm{NO}^{\bullet}$ bioavailability. $\mathrm{NO}^{\bullet}$ is a vasoactive molecule which has an important role in vascular homeostasis maintenance [42]. The decrease of $\mathrm{NO}^{\bullet}$ bioavailability is considered an important indicator of vascular endothelial dysfunction contributing to atherosclerosis development [43]. Our experimental results showed a reduced bioavailability of NO* in Lipofundin-treated rabbits compared with controls. This deleterious effect for vascular function may contribute with the Lipofundin-induced atherogenic development.

\section{Conclusions}

In summary, the present study demonstrated that Lipofundin $20 \%$ induces hyperlipidemia, thereby promoting a systemic and aortic OS and also contributing with atherosclerotic lesions formation in NZW rabbits. This work shows novel evidences of Lipofundin-induced oxidative damages on lipids and proteins, the impairment of antioxidant status, and the reduction of nitric oxide levels. These results reinforce the attractive characteristics of Lipofundin to be used as an inductor of experimental atherosclerosis in rabbits. The reduction of experimental time and the associated costs, compared with other established models, is in our opinion the main advantage of this animal model of atherosclerosis.

\section{Conflict of Interests}

There are not conflict of interests.

\section{Acknowledgments}

The authors gratefully acknowledge the support from the Center of Molecular Immunology (Havana, Cuba) and the technical assistance of Dalia R. Álvarez.

\section{References}

[1] H. Tavori, M. Aviram, S. Khatib et al., "Human carotid atherosclerotic plaque increases oxidative state of macrophages and low-density lipoproteins, whereas paraoxonase 1 (PON1) decreases such atherogenic effects," Free Radical Biology and Medicine, vol. 46, no. 5, pp. 607-615, 2009.

[2] K. J. Williams and I. Tabas, "The response-to-retention hypothesis of early atherogenesis," Arteriosclerosis, Thrombosis, and Vascular Biology, vol. 15, no. 5, pp. 551-562, 1995.

[3] D. Steinberg, S. Parthasarathy, T. E. Carew, J. C. Khoo, and J. L. Witztum, "Beyond cholesterol: modifications of low-density lipoprotein that increase its atherogenicity," The New England Journal of Medicine, vol. 320, no. 14, pp. 915-924, 1989.

[4] D. Steinberg, "Atherogenesis in perspective: hypercholesterolemia and inflammation as partners in crime," Nature Medicine, vol. 8, no. 11, pp. 1211-1217, 2002.

[5] R. Stocker and J. F. Keaney, "Role of oxidative modifications in atherosclerosis," Physiological Reviews, vol. 84, no. 4, pp. 13811478, 2004.
[6] A. Scoczynska, "The role of lipids in atherogenesis," Postępy Higieny i Medycyny Doświadczalnej, vol. 59, pp. 346-357, 2005.

[7] H. Jellinek, J. Harsing, and S. Fuzesi, "A new model for arteriosclerosis. An electron-microscopic study of the lesions induced by i.v. administered fat," Atherosclerosis, vol. 43, no. 1, pp. 7-8, 1982.

[8] M. Noa and R. Más, "Ateromixol y lesión ateroesclerótica en Conejos inducida por Lipofundin," Progresos en Ciencias Médicas, vol. 6, pp. 14-19, 1992.

[9] M. M. Bradford, "A rapid and sensitive method for the quantitation of microgram quantities of protein utilizing the principle of protein dye binding," Analytical Biochemistry, vol. 72, no. 1-2, pp. 248-254, 1976.

[10] Boehringer Mannheim, Biochemica Information. A Revised Biochemical Reference Source. Enzymes for Routine, Boehringer Mannheim, Berlin, Germany, 1st edition, 1987.

[11] J. Sedlak and R. H. Lindsay, "Estimation of total, proteinbound, and nonprotein sulfhydryl groups in tissue with Ellman's reagent," Analytical Biochemistry, vol. 25, no. C, pp. 192-205, 1968.

[12] V. Witko-Sarsat, M. Friedlander, T. N. Khoa et al., "Advanced oxidation protein products as novel mediators of inflammation and monocyte activation in chronic renal failure," Journal of Immunology, vol. 161, no. 5, pp. 2524-2532, 1998.

[13] H. Esterbauer and K. H. Cheeseman, "Determination of aldehydic lipid peroxidation products: malonaldehyde and 4hydroxynonenal," Methods in Enzymology, vol. 186, pp. 407421, 1990.

[14] I. Erdelmeier, D. Gerard-Monnier, J. C. Yadan, and J. Chaudiere, "Reactions of N-methyl-2-phenylindole with malondialdehyde and 4-hydroxyalkenals. Mechanistic aspects of the colorimetric assay of lipid peroxidation," Chemical Research in Toxicology, vol. 11, pp. 1184-1194, 1998.

[15] G. Ozdemirler, G. Mehmetcik, S. Oztezcan, G. Toker, A. Sivas, and M. Uysal, "Peroxidation potential and antioxidant activity of serum in patients with diabetes mellitus and myocardial infarction," Hormone and Metabolic Research, vol. 27, pp. 194196, 1995.

[16] D. L. Granger, R. R. Taintor, K. S. Boockvar, and J. B. Hibbs, "Determination of nitrate and nitrite in biological samples using bacterial nitrate reductase coupled with the Griess reaction," Methods, vol. 7, no. 1, pp. 78-83, 1995.

[17] T. B. Horwich, A. F. Hernandez, D. Dai, C. W. Yancy, and G. C. Fonarow, "Cholesterol levels and in-hospital mortality in patients with acute decompensated heart failure," American Heart Journal, vol. 156, no. 6, pp. 1170-1176, 2008.

[18] S. J. Hur, M. Du, K. Nam, M. Williamson, and D. U. Ahn, "Effect of dietary fats on blood cholesterol and lipid and the development of atherosclerosis in rabbits," Nutrition Research, vol. 25, no. 10, pp. 925-935, 2005.

[19] K. S. Jain, M. K. Kathiravan, R. S. Somani, and C. J. Shishoo, "The biology and chemistry of hyperlipidemia," Bioorganic and Medicinal Chemistry, vol. 15, no. 14, pp. 4674-4699, 2007.

[20] L. A. Carlson, "Studies on the fat emulsion Intralipid. I. Association of serum proteins to Intralipid triglyceride particles (ITP)," Scandinavian Journal of Clinical and Laboratory Investigation, vol. 40, no. 2, pp. 139-144, 1980.

[21] S. Hailer and G. Wolfram, "Influence of artificial fat emulsions on the composition of serum lipoproteins in humans," American Journal of Clinical Nutrition, vol. 43, no. 2, pp. 225233, 1986.

[22] J. R. Wetterau and D. B. Zilversmit, "Purification and characterization of microsomal triglyceride and cholesteryl ester 
transfer protein from bovine liver microsomes," Chemistry and Physics of Lipids, vol. 38, no. 1-2, pp. 205-222, 1985.

[23] R. Frikke-Schmidt, B. G. Nordestgaard, M. C. A. Stene et al., "Association of loss-of-function mutations in the ABCA1 gene with high-density lipoprotein cholesterol levels and risk of ischemic heart disease," Journal of the American Medical Association, vol. 299, no. 21, pp. 2524-2532, 2008.

[24] B. F. Asztalos and E. J. Schaefer, "High-density lipoprotein subpopulations in pathologic conditions," American Journal of Cardiology, vol. 91, no. 7, 2003.

[25] E. M. Tsompanidi, M. S. Brinkmeier, E. H. Fotiadou, S. M. Giakoumi, and K. E. Kypreos, "HDL biogenesis and functions: role of HDL quality and quantity in atherosclerosis," Atherosclerosis, vol. 208, no. 1, pp. 3-9, 2010.

[26] D. P. Jones, "Redefining oxidative stress," Antioxidants and Redox Signaling, vol. 8, no. 9-10, pp. 1865-1879, 2006.

[27] M. Sadidi, S. I. Lentz, and E. L. Feldman, "Hydrogen peroxide-induced Akt phosphorylation regulates Bax activation," Biochimie, vol. 91, no. 5, pp. 577-585, 2009.

[28] S. Ashfaq, J. L. Abramson, D. P. Jones et al., "The relationship between plasma levels of oxidized and reduced thiols and early atherosclerosis in healthy adults," Journal of the American College of Cardiology, vol. 47, no. 5, pp. 1005-1011, 2006.

[29] R. Zhao and G. X. Shen, "Functional modulation of antioxidant enzymes in vascular endothelial cells by glycated LDL," Atherosclerosis, vol. 179, no. 2, pp. 277-284, 2005.

[30] L. D. Roche, E. A. Medina, Y. Hernández-Matos, M. A. Bécquer Viart, A. M. Vázquez López, and E. FernándezSánchez, "High levels of lipid peroxidation induced by Lipofundin administration correlate with atherosclerotic lesions in rabbits," Pharmacologyonline, vol. 3, pp. 727-736, 2010.

[31] S. Tani, K. Nagao, T. Anazawa et al., "Association of plasma level of malondialdehyde-modified low-density lipoprotein with coronary plaque morphology in patients with coronary spastic angina: implication of acute coronary events," International Journal of Cardiology, vol. 135, no. 2, pp. 202-206, 2009.

[32] G. Martínez-Sánchez, I. Popov, G. Pérez-Davison et al., "Contribution to characterization of oxidative stress in diabetic patients with macroangiopatic complications," Acta Farmaceutica Bonaerense, vol. 24, no. 2, pp. 197-203, 2005.

[33] J. M. McCord and I. Fridovich, "Superoxide dismutase. An enzymic function for erythrocuprein (hemocuprein)," Journal of Biological Chemistry, vol. 244, no. 22, pp. 6049-6055, 1969.

[34] B. M. Babior, J. D. Lambeth, and W. Nauseef, "The neutrophil NADPH oxidase," Archives of Biochemistry and Biophysics, vol. 397, no. 2, pp. 342-344, 2002.

[35] P. Stralin, K. Karlson, B. O. Johansson, and S. L. Marklund, "The interstitium of the human arterial wall contain very large amounts of extracellular superoxide dismutase," Arteriosclerosis, Thrombosis, and Vascular Biology, vol. 20, pp. 32-36, 1995.

[36] R. Ginnan, B. J. Guikema, K. E. Halligan, H. A. Singer, and D. Jourd'heuil, "Regulation of smooth muscle by inducible nitric oxide synthase and NADPH oxidase in vascular proliferative diseases," Free Radical Biology and Medicine, vol. 44, no. 7, pp. 1232-1245, 2008.

[37] A. Deisseroth and A. L. Dounce, "Catalase: physical and chemical properties, mechanism of catalysis, and physiological role," Physiological Reviews, vol. 50, no. 3, pp. 319-375, 1970.

[38] S. J. Lin, S. K. Shyue, M. C. Shih et al., "Superoxide dismutase and catalase inhibit oxidized low-density lipoprotein-induced human aortic smooth muscle cell proliferation: role of cell-cycle regulation, mitogen-activated protein kinases, and transcription factors," Atherosclerosis, vol. 190, no. 1, pp. 124 $134,2007$.
[39] M. R. Brown, F. J. Miller, W. G. Li et al., "Overexpression of human catalase inhibits proliferation and promotes apoptosis in vascular smooth muscle cells," Circulation Research, vol. 85, no. 6, pp. 524-533, 1999.

[40] M. L. Circu and T. Y. Aw, "Glutathione and apoptosis," Free Radical Research, vol. 42, no. 8, pp. 689-706, 2008.

[41] I. Rahman, S. K. Biswas, L. A. Jimenez, M. Torres, and H. J. Forman, "Glutathione, stress responses, and redox signaling in lung inflammation," Antioxidants and Redox Signaling, vol. 7, no. 1-2, pp. 42-59, 2005.

[42] T. Hiyash, K. Yano, H. Matusri, H. Yakao, Y. Hattori, and A. Igushi, "Nitric oxide and endothelial senescence," Pharmacology' Therapeutics, vol. 120, pp. 333-339, 2008.

[43] P. Pacher, J. S. Beckman, and L. Liaudet, "Nitric oxide and peroxynitrite in health and disease," Physiological Reviews, vol. 87, no. 1, pp. 315-424, 2007. 


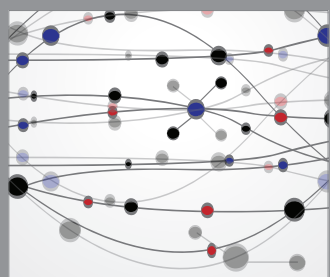

The Scientific World Journal
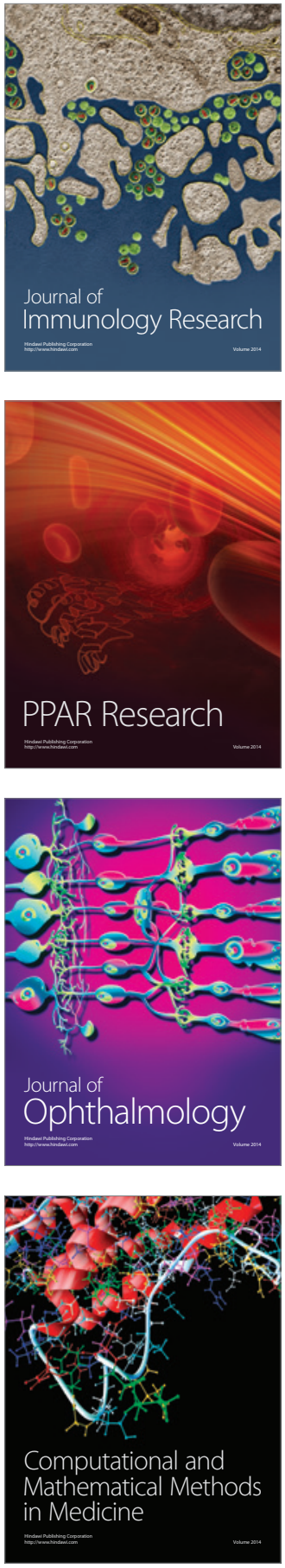

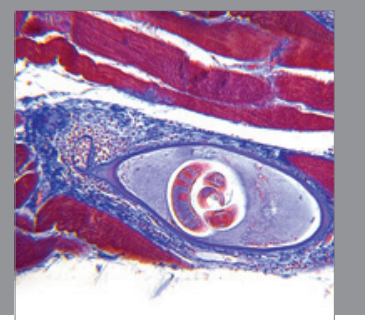

Gastroenterology

Research and Practice
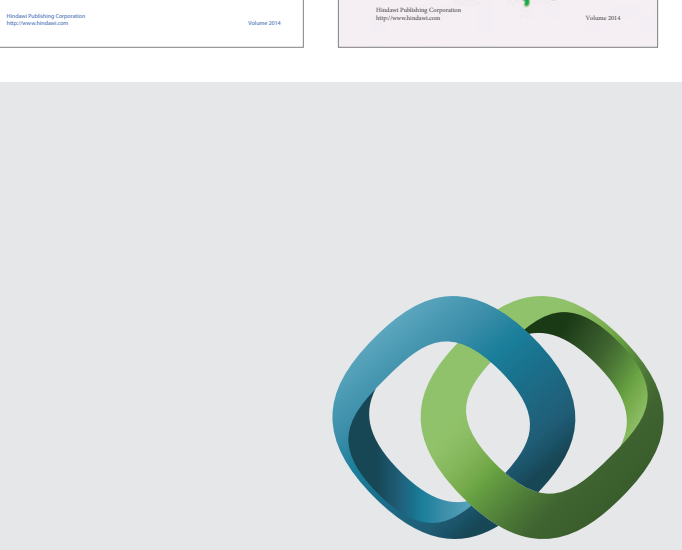

\section{Hindawi}

Submit your manuscripts at

http://www.hindawi.com
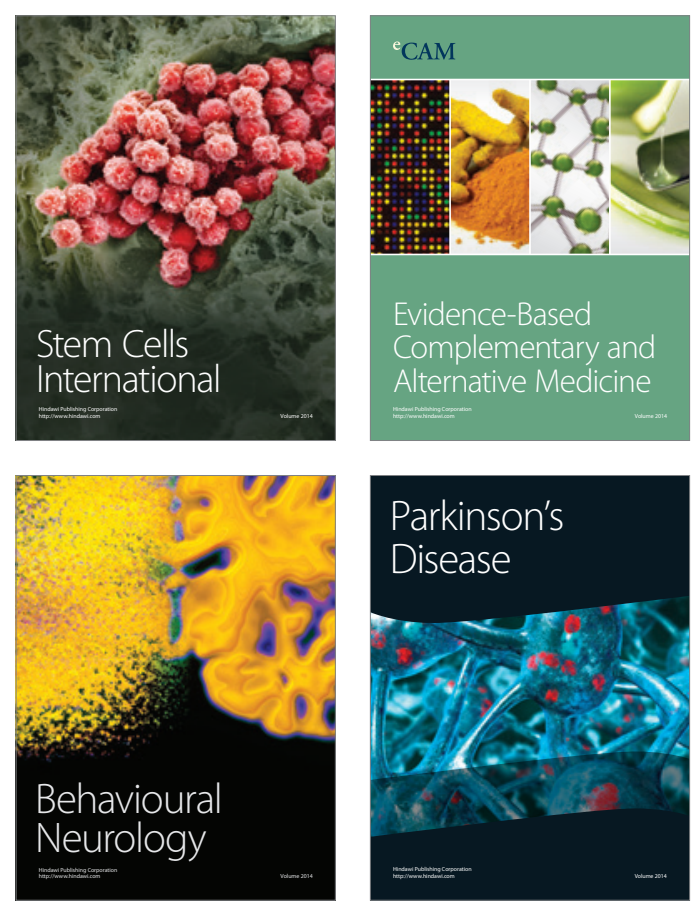

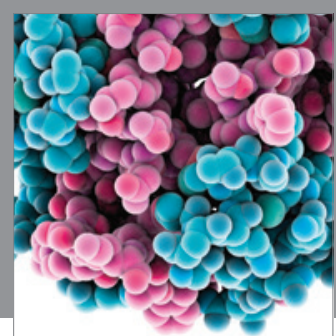

Journal of
Diabetes Research

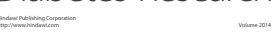

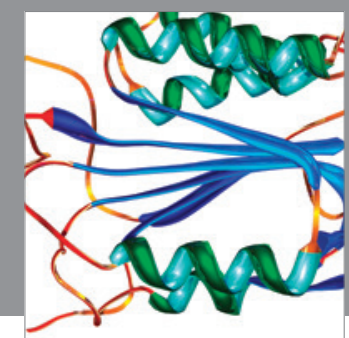

Disease Markers
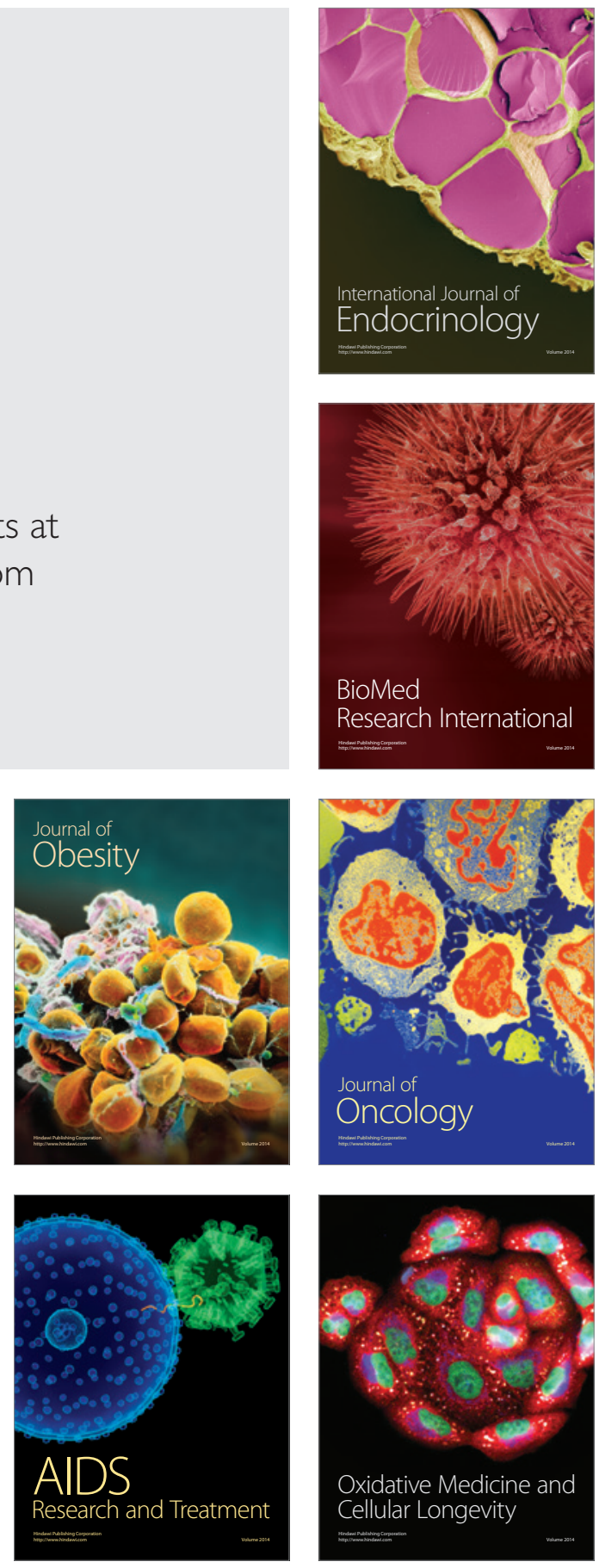